COMPETING FINANCIAL INTERESTS

The authors declare competing financial interests: details are available in the online version of the paper (doi:10.1038/nbt.3524).

Emanuele Libertini ${ }^{1}$, Simon C Heath ${ }^{2}$, Rifat A Hamoudi ${ }^{3}$, Marta Gut ${ }^{2}$, Michael J Ziller ${ }^{4-6}$, Javier Herrero ${ }^{7}$, Agata Czyz ${ }^{8}$, Victor Ruotti ${ }^{8}$, Hendrik G Stunnenberg ${ }^{9}$, Mattia Frontini ${ }^{10-12}$, Willem H Ouwehand ${ }^{10-13}$, Alexander Meissner ${ }^{4-6}$, Ivo G Gut ${ }^{2}$ \& Stephan Beck ${ }^{1}$

${ }^{1}$ Medical Genomics, UCL Cancer Institute, University College London, London, UK. ${ }^{2}$ Centro Nacional de Análisis Genómico (CNAG), Parc Científic de Barcelona, Barcelona, Spain. ${ }^{3}$ Division of Surgery and Interventional Science, University College London, London, UK. ${ }^{4}$ Broad Institute of MIT and Harvard, Cambridge, Massachusetts, USA. ${ }^{5}$ Harvard Stem Cell Institute, Cambridge, Massachusetts, USA. ${ }^{6}$ Department of Stem Cell and Regenerative Biology, Harvard University, Cambridge, Massachusetts, USA. ${ }^{7}$ Bill Lyons Informatics Centre, UCL Cancer Institute, University College London, London, UK. ${ }^{8}$ Illumina Inc., San Diego, California, USA. ${ }^{9}$ Department of Molecular Biology, Radboud University Nijmegen, Nijmegen, Netherlands. ${ }^{10}$ Department of Haematology, University of Cambridge,
Cambridge, United Kingdom. ${ }^{11}$ National Health Service Blood and Transplant, Cambridge Biomedical Campus, Cambridge, UK. ${ }^{12}$ British Heart Foundation Centre of Excellence, University of Cambridge, Cambridge, UK. ${ }^{13}$ Wellcome Trust Sanger Institute, Wellcome Trust Genome Campus, Hinxton, Cambridge, UK.

e-mail:emanuele.libertini@ucl.ac.ukor s.beck@ucl.ac.uk

Published online 27 June 2016;

doi:10.1038/nbt.3524

1. Bock, C. et al. Nat. Biotechnol. 28, 1106-1114 (2010).

2. Harris, R.A. et al. Nat. Biotechnol. 28, 1097-1105 (2010)

3. Beck, S. Nat. Biotechnol. 28, 1026-1028 (2010).

4. Libertini, E. et al. Nat. Commun. 7, 11306 (2016).

5. Gu, H. et al. Nat. Protoc. 6, 468-481 (2011).

6. Ziller, M.J. et al. Nature 500, 477-481 (2013).

7. Lister, R. et al. Nature 462, 315-322 (2009).

8. Li, Y. et al. PLoS Biol. 8, e1000533 (2010).

9. Hansen, K.D., Langmead, B. \& Irizarry, R.A. Genome Biol. 13, R83 (2012).

10. Dolzhenko, E. \& Smith, A.D. BMC Bioinformatics 15, 215 (2014).

11. Down, T.A. et al. Nat. Biotechnol. 26, 779-785 (2008).

12. Satterlee, J.S., Schübeler, D. \& Ng, H.H. Nat. Biotechnol. 28, 1039-1044 (2010).

13. Adams, D. et al. Nat. Biotechnol. 30, 224-226 (2012).

\title{
How China can enhance adoption of biotech crops
}

\section{To the Editor:}

The development of new approaches for creating genetically modified (GM) crops continues apace, yet societal and public policy decisions slow or prevent their adoption. This is unfortunate, especially in China, which has so much to gain and has done much to harness the power of biotech for the public good. China, the most populous country in the world, was until recently classified as a developing country $^{1}$. As migration from the rural to the urban areas continues, and a burgeoning middle-class is developing, food security and environmental stewardship have become national goals. GM crops should be part of the solution. However, the voices of anti-GM groups have become louder and more difficult for the government to ignore, so officials have been cautious in promoting GM technology and implementing its adoption. In the "No. 1 Central Document" published in January, the government touted "agricultural modernization" with a push to "more efficient, inclusive and environment-friendly" farming. With respect to implementation of GM products, we believe the government should be doing more, not only for its own people but also as a world leader affecting global policy for agricultural innovation. For that to happen, two important needs should be integrated into policy.

First, efforts aiming to develop GM crops should be focused on balancing the benefits to the producer, consumer and environment. Currently, the traditional sole focus of increasing yield is inappropriate ${ }^{2,3}$; this must be expanded to include production of high-quality, safe and lowcost food, produced in an environmentally responsible manner. The Chinese government has already stated this in its “No. 1 Central Document." Therefore, GM technology that reduces pesticide and labor inputs fits in well with this government charge. Advances in gene editing may even supplant the more traditional forms of genetic engineering. A successful example of editing was demonstrated with hexaploid bread wheat ${ }^{4,5}$ that was developed by Chinese scientists for the domestic market. Investment in Chinese biotech can also help develop the appropriate biotech products for the world market that will have consumer and environmental benefits, as well helping other countries build their scientific capacity.

Second, equally if not more important, is the need for the Chinese government to develop a committed and well-funded educational program on biotech for the public. Several recent studies indicate that an increasing proportion of the Chinese public opposes GM technology $y^{6,7}$. The increased frequency of food safety scandals in China has caused consumers to be more wary of their food and more skeptical of the government; and with so much misinformation readily available about GM, biotech crops may become collateral damage. Custom-designed educational programs are urgently needed to educate consumers about the safety of GM crops and the foods derived from them. We appeal to the government to develop such programs and increase public dialog. Chinese scientists will be key in this effort because they have the most knowledge about biotech and are trusted by the general public. Additionally, they are best able to identify and correct the misinformation, spread by anti-science groups opposed to GM crops, which permeates some of the news media. It is important that researchers gain the confidence of the public so public policies on GM crops and biotech can move forward.

\section{ACKNOWLEDGMENTS}

This work was supported by the China Postdoctoral Science Foundation (No. 2016M591136).

\section{COMPETING FINANCIAL INTERESTS}

The authors declare no competing financial interests.

\section{Fei Han ${ }^{1}$, Anthony M Shelton ${ }^{2}$ \& Dingyang Zhou ${ }^{3}$}

${ }^{1}$ State Information Center, Beijing, China. ${ }^{2}$ Department of Entomology, Cornell University/ New York State Agricultural Experiment Station (NYSAES), Geneva, New York, USA. ${ }^{3}$ College of Resources Science and Technology, Beijing Normal University, Beijing, China.

e-mail:cauhanfei@126.com,ams5@cornell.edu orzhoudy@bnu.edu.cn.

1. International Monetary Fund. World Economic Outlook Report: Uneven Growth-Short- and Long-Term Factors (IMF, 2015)

2. Huang, J., Hu, R., Cai, J. \& Wang, X. Nat. Biotechnol 30, 1007 (2012)

3. Huang, J., Rozelle, S., Pray, C. \& Wang, Q. Science 295, 674-676 (2002)

4. Shan, Q. et al. Nat. Biotechnol. 31, 686-688 (2013).

5. Wang, Y. et al. Nat. Biotechnol. 32, 947-951 (2014).

6. Han, F. et al. PLoS One 10, e0139114 (2015).

7. Huang, J.K. \& Peng, B. J. Integr. Agric. 14, 23912400 (2015). 